\title{
UJI PERSAMAAN LANGMUIR DAN CHAPMAN PADA DAYA SERAP ZEOLIT ALAM TERAKTIVASI TERHADAP LOGAM CHROM
}

\author{
1
}

\author{
Syarifah Aini $^{1}$, Hari Dwi Wahyudi ${ }^{2}$ \\ Jurusan Teknik Sipil, Fakultas Teknik, Universitas Widya Dharma Klaten \\ aini07931@gmail.com
}

\begin{abstract}
Abstrak
Logam chrom termasuk limbah logam berat yang perlu dilakukan pengolahan lebih lanjut dengan menggunakan adsorben. Zeolit adalah adsorben yang cocok untuk menyerap logam chrom karena zeolit merupakan mineral alam yang mempunyai luas permukaan aktif per satuan massa yang besar dan daya afinitas yang cukup kuat. Tujuan dari penelitian ini adalah menentukan daya serap zeolit alam teraktivasi terhadap logam chrom melalui model kesetimbangan isoterm adsorpsi yaitu uji persamaan Langmuir dan Chapman beserta nilai nilai parameternya. Penelitian ini mengunakan metode penerapan model kesetimbangan adsorpsi isoterm yaitu Adsorpsi Isoterm Langmuir, dan Persamaan Sigmoidal Chapman. Dari kedua model ini dilakukan fitting data menggunakan program Excel kemudian model yang cocok akan dapat diamati dari visualisasi dan minimasi $R$-squared value. Model yang cocok dapat digunakan untuk mengetahui daya serap zeolit maksimal terhadap logam chrom. Hasil penelitian menunjukkan bahwa persamaan Chapman lebih cocok digunakan untuk menyelesaikan kasus adsorpsi logam chrom oleh zeolit, baik zeolit alam maupun zeolit alam teraktivasi asam sulfat. Untuk menentukan daya serap zeolit maksimal, diambil dari persamaan Chapman yaitu nilai a nya. Dari kedua proses adsorpsi, nilai a yang terbesar yaitu isoterm adsorpsi logam chrom oleh zeolit teraktivasi asam sulfat, sebesar $418,3117 \mathrm{mg} / \mathrm{g}$. Zeolit alam yang sudah teraktivasi oleh asam sulfat
\end{abstract}

lebih reaktif dibandingkan yang belum teraktivasi asam sulfat.

Kata Kunci: Adsorben; Isoterm Chapman; Model Kesetimbangan Adsorpsi; Zeolit

\section{Pendahuluan}

Limbah logam berat seperti chromium, cadmium, timbal dan air raksa yang dibuang ke perairan oleh pelaku industri disebabkan karena sulitnya proses pemisahan ion logam tersebut dengan menggunakan proses pengendapan atau koagulasi. Limbah chromium ini perlu dilakukan pengolahan lebih lanjut dengan menggunakan teknik-teknik lain seperti pertukaran ion maupun menggunakan adsorben (zat penyerap). Adsorben yang digunakan dalam penelitian ini adalah zeolit, karena zeolit merupakan mineral alam yang mempunyai luas permukaan aktif per satuan massa yang besar dan mempunyai daya afinitas yang cukup kuat (Lestari, 2010).

Tujuan dari penelitian ini adalah menentukan daya serap zeolit alam teraktivasi terhadap logam chrom melalui model kesetimbangan isoterm adsorpsi yaitu uji persamaan Langmuir dan Chapman beserta nilai nilai parameternya.

Meskipun adsorpsi dapat juga terjadi di permukaan adsorben padat, di dalam makropori dan mesopori, namun luas permukaaan ( surface area) adsorben padat sangat kecil sekali bila dibandingkan luas permukaan mikropori (internal surface area), sehingga ini biasanya diabaikan. Ketika laju adsorpsi sama dengan laju desorpsi maka kesetimbangan telah tercapai dan kapasitas adsorben dapat diketahui. Secara teori, kapasitas penjerapan suatu adsorben terhadap

\footnotetext{
${ }^{1}$ Aini, Syarifah. Wahyudi, Hari Dwi. 2018. UJ PERSAMAAN LANGMUIR DAN CHAPMAN PADA DAYA SERAP ZEOLIT ALAM TERAKTIVASI TERHADAP LOGAM CHROM. preprint
} 
kontaminan dapat dihitung menggunakan persamaan isoterm adsorpsi (Metcalf dan Eddy, 2003).

Keberhasilan proses adsorpsi padat - cair tergantung pada performa adsorben yang digunakan, baik dalam hal kesetimbangan maupun kinetikanya. Adsorben dengan kapasitas yang tinggi (porous) tetapi memiliki afinitas yang rendah akan menjerap molekul cairan yang rendah, karena molekul cairan membutuhkan waktu yang lama untuk mencapai permukaan padatan. Sementara adsorben dengan afinitas yang tinggi tetapi pori - pori sedikit hanya mampu menjerap molekul cairan dalam jumlah sedikit, sehingga adsorpsi kurang sempurna (Laksito, 2008).

Jumlah adsorbat yang dapat terjerap oleh absorben merupakan fungsi dari karakteristik dan konsentrasi adsorbat serta temperatur. Karakteristik adsorbat seperti kelarutan, struktur molekul, berat molekul, polaritas dan hydrocarbon saturation merupakan hal yang penting. Pada umumnya, jumlah bahan yang teradsorpsi dapat dihitung sebagai fungsi dari konsentrasi pada temperatur konstan, dan fungsi ini dikenal sebagai Adsorption Isotherm (Metcalf dan Eddy, 2003).

Penelitian tentang "Adsorpsi Logam Chrom dengan Zeolit Alam Teraktivasi Asam Sulfat" yang dilakukan oleh Khoirul Wahyu Wahidatun (2014). Penelitian ini bertujuan membandingkan karakter zeolit alam dengan zeolit alam teraktivasi asam sulfat, mengetahui pola isoterm, model kinetika, dan sistem temodinamika dari adsorpsi logam chrom oleh zeolit alam dan zeolit alam teraktivasi. Hasil penelitian menunjukkan terdapat perbedaan karakter antara zeolit alam dan zeolit alam teraktivasi, model isoterm mengikuti model isoterm Freundlich, kinetika reaksi untuk zeolit alam mengikuti model kinetika pseudo orde 1 sedangkan zeolit alam teraktivasi mengikuti model kinetika pseudo orde 2, model termodinamika untuk zeolit alam mengikuti reaksi eksotermis (energi Gibbs negatif) sedangkan untuk zeolit alam teraktivasi mengikuti reaksi endotermis (energi Gibbs positif).

\section{Metode Penelitian \\ Pengambilan Data Sekunder}

Data Sekunder diambil dari data penelitian yang dilakukan oleh Wahidatun (2014), data yang didapat adalah konsentrasi logam chrom pada saat setimbang $\left(C_{e}\right)$ dan konsentrasi logam chrom yang teradsorpsi oleh zeolit pada saat setimbang $\left(q_{e}\right)$ pada berbagai konsentrasi logam chrom dalam sampel mula-mula $\left(C_{0}\right)$ yaitu konsentrasi $10 \mathrm{ppm}$, 30 ppm, 50 ppm, dan 70 ppm. Data ini diambil dari percobaan dengan sampel yang menggunakan zeolit alam dan zeolit alam yang teraktivasi asam sulfat.

\section{Model dan Analisis Data}

Dari data sekunder tersebut dilakukan fitting data dengan menggunakan program Excel berdasarkan model kesetimbangan adsorpsi isoterm Langmuir dan Chapman kemudian model yang cocok akan dapat diamati dari visualisasi dan minimasi $R$-squared value. Model yang cocok dapat digunakan untuk mengetahui daya serap zeolit maksimal terhadap logam chrom.

Persamaan Langmuir berdasarkan asumsi bahwa adsorpsi terjadi secara monolayer, bersifat reversible dan dinyatakan sebagai (Metcalf dan Eddy, 2003) :

$$
q_{e}=\frac{x}{m}=\frac{a b C_{e}}{1+b C_{e}}
$$

dimana a adalah konsentrasi maksimal di fase padat $(\mathrm{mg} / \mathrm{g})$ dan $\mathrm{b}$ adalah tetapan kesetimbangan (l/mg).

Persamaan Chapman menyatakan adsorpsi sangat kecil pada konsentrasi rendah namun adsorpsi akan meningkat dengan semakin meningkatnya konsentrasi larutan, persamaan sigmoidal Chapman dinyatakan sebagai (Chatterjee,dkk., 2010):

$$
q_{e}=\propto\left(1-e^{-\beta \cdot c_{e}}\right)^{\gamma}
$$

dimana $\alpha$ adalah konsentrasi maksimal adsorben $(\mathrm{mg} / \mathrm{g})$ dan $\beta, Y$ adalah tetapan kesetimbangan. 
Kadar chromium yang teradsorpsi oleh zeolit pada saat setimbang dihitung dengan menggunakan persamaan berikut :

$$
q_{e}=\left(\frac{V}{m}\right) \cdot C_{0}+q_{e 0}-\left(\frac{V}{m}\right) \cdot C_{e}
$$

dimana $q_{e}$ adalah massa chrom yang teradsorpsi $(x)$ per massa zeolit $(m)$ pada saat setimbang ( $\mathrm{mg} \mathrm{C} / \mathrm{g}$ zeolit), qeo adalah konsentrasi chrom di dalam zeolit mula mula (mg Cl $\mathrm{g}$ zeolit), $\mathrm{C}_{0}$ adalah konsentrasi chrom dalam cairan mula-mula (mg/l), $\mathrm{m}$ adalah massa zeolit ( $\mathrm{g}$ ), $\mathrm{V}$ adalah volume cairan (I), $C_{e}$ adalah konsentrasi chrom dalam cairan saat setimbang ( $\mathrm{mg} / \mathrm{l})$.

\section{Hasil dan Pembahasan}

Adsorpsi Logam Chrom dengan Zeolit Alam

Percobaan kesetimbangan adsorpsi logam chrom oleh zeolit alam, dapat dilihat pada Tabel 1.

Tabel 1. Data dan Perhitungan Adsorpsi Isoterm Logam Chrom oleh Zeolit Alam

\begin{tabular}{clllll}
\hline $\begin{array}{l}\text { Co } \\
(\mathrm{ppm})\end{array}$ & $\begin{array}{l}\text { Ce } \\
(\mathrm{ppm})\end{array}$ & $\begin{array}{l}\text { qe } \\
(\mathrm{mg} / \mathrm{g})\end{array}$ & $\begin{array}{l}\text { Ce/qe } \\
(\mathrm{g} / \mathrm{l})\end{array}$ & $\begin{array}{l}\text { Log } \\
\text { exp } \\
(\mathrm{Ce})\end{array}$ & $\begin{array}{l}\text { Log } \\
\text { qe }\end{array}$ \\
\hline 10 & 0,088 & 0,248 & 0,355 & 0,038 & $-0,61$ \\
30 & 3,794 & 0,656 & 5,784 & 1,648 & $-0,18$ \\
50 & 3,688 & 1,158 & 3,185 & 1,602 & 0,064 \\
70 & 4,902 & 1,628 & 3,011 & 2,129 & 0,212 \\
\hline
\end{tabular}

Persamaan (1), persamaan isoterm Lanmuir diubah menjadi bentuk linier, menjadi:

$$
\frac{C_{e}}{q_{e}}=\frac{1}{a} C_{e}+\frac{1}{a b}
$$

Dari persamaan (4), kemudian dibuat grafik linierisasi, dengan data pada Tabel 1 menjadi:

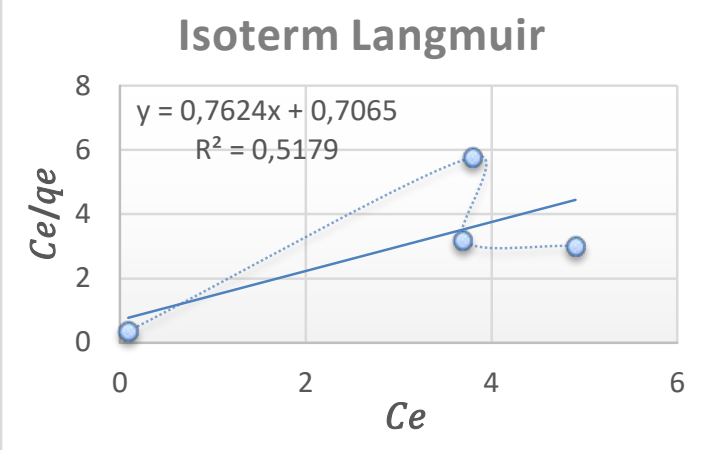

Persamaan yang diperoleh dari grafik, menghasilkan konsentrasi maksimal di fase padat $(\mathrm{a})=1,3116 \mathrm{mg} / \mathrm{g}$ dan tetapan kesetimbangan Langmuir $(b)=1,0791$ $\mathrm{l} / \mathrm{mg}$.

Persamaan (2), persamaan Chapman diubah menjadi bentuk linier, menjadi:

$\log q_{e}=\log \alpha-\gamma \log e^{-\beta} \cdot \log e^{c_{e}}$

Dari persamaan (5), kemudian dibuat grafik linierisasi, menjadi:

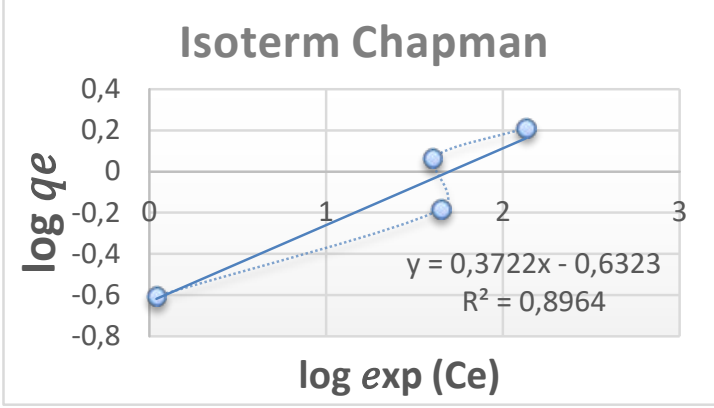

Maka diperoleh konsentrasi maksimal adsorben $(\alpha)=0,2332 \mathrm{mg} / \mathrm{g}$ dan tetapan kesetimbangan $-\gamma \log e^{-\beta}=0,3722$.

\section{Adsorpsi Logam Chrom dengan Zeolit Alam Teraktivasi Asam Sulfat \\ Percobaan kesetimbangan adsorpsi} logam chrom oleh zeolit alam teraktivasi asam sulfat, dapat dilihat pada Tabel 2 .

Tabel 2. Data dan Perhitungan Adsorpsi Isoterm Logam Chrom oleh Zeolit Alam Teraktivasi Asam Sulfat

\begin{tabular}{cccccc}
\hline $\begin{array}{l}\text { Co } \\
(\mathrm{ppm})\end{array}$ & $\begin{array}{l}\text { Ce } \\
(\mathrm{ppm})\end{array}$ & $\begin{array}{l}\mathrm{qe} \\
(\mathrm{mg} / \mathrm{g})\end{array}$ & $\begin{array}{l}\text { Ce/qe } \\
(\mathrm{g} / \mathrm{l})\end{array}$ & $\begin{array}{l}\text { Log } \\
\text { exp } \\
(\mathrm{Ce})\end{array}$ & $\begin{array}{l}\text { Log } \\
\text { qe }\end{array}$ \\
\hline 10 & 4,412 & 0,14 & 31,51 & 1,916 & $-0,85$ \\
30 & 5,615 & 0,61 & 9,205 & 2,439 & $-0,21$ \\
50 & 5,424 & 1,114 & 4,869 & 2,356 & 0,047 \\
70 & 7,032 & 1,574 & 4,468 & 3,054 & 0,197 \\
\hline
\end{tabular}

Linierisasi grafik isoterm Langmuir dengan data pada Tabel 2 menjadi: 


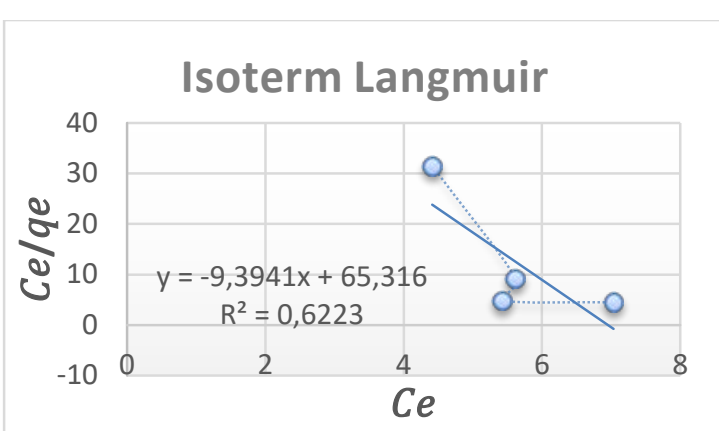

Tanda negatif dalam persamaan menunjukkan gradient kemiringan kurva ke kiri, dan untuk menentukan parameter isoterm Langmuir, tetap mengambil angka positif. Maka diperoleh konsentrasi maksimal di fase padat (a) $=0,1064 \mathrm{mg} / \mathrm{g}$ dan tetapan kesetimbangan Langmuir $(b)=$ $0,1438 \mathrm{l} / \mathrm{mg}$.

Linierisasi grafik isoterm Chapman dengan data pada Tabel 2 menjadi:

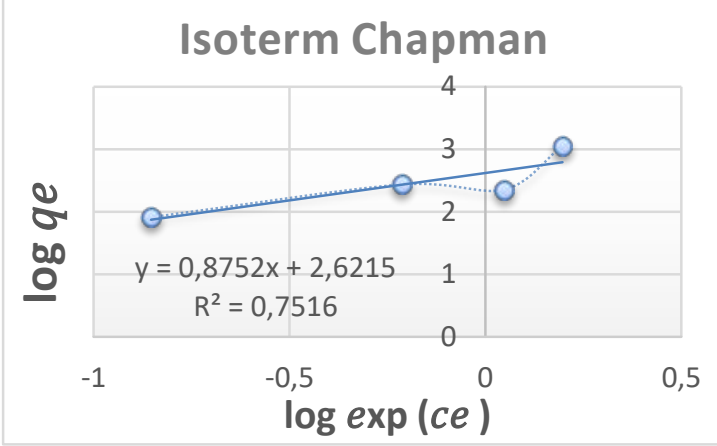

Dari grafik diperoleh konsentrasi maksimal adsorben $(\alpha)=418,3117 \mathrm{mg} / \mathrm{g}$ dan tetapan kesetimbangan $-\gamma \log e^{-\beta}=0,8752$.

\section{Parameter Kesetimbangan Adsorpsi}

Nilai parameter kesetimbangan adsorpsi dapat dilihat dalam Tabel 3.

Dilihat dari $R$-squared value $\left(R^{2}\right)$, persamaan Chapman lebih mendekati $R^{2}=$ 1 , itu artinya persamaan Chapman lebih cocok digunakan untuk menyelesaikan kasus adsorpsi logam chrom oleh zeolit, baik zeolit alam maupun zeolit alam teraktivasi asam sulfat. Untuk menentukan daya serap zeolit maksimal, diambil juga dari persamaan Chapman yaitu nilai a nya.

Dilihat dari kedua proses adsorpsi, maka nilai a yang terbesar yaitu isoterm adsorpsi logam chrom oleh zeolit teraktivasi asam sulfat, yaitu sebesar $418,3117 \mathrm{mg} / \mathrm{g}$. Ini menunjukkan bahwa zeolit alam yang sudah teraktivasi oleh asam sulfat lebih reaktif dibandingkan yang belum teraktivasi asam sulfat, karena dengan aktivasi akan memperbesar internal surface area, yang menyebabkan adsorben tersebut sangat porous/ porsi volume porinya besar, sehingga kapasitas penjerapannya menjadi besar (Metcalf dan Eddy, 2003).

Persamaan Langmuir sebenarnya juga mampu mewakili dalam kasus penelitian ini, karena proses adsorpsi logam chrom oleh zeolit terjadi pada lapisan tunggal / monolayer dan mampu menggambarkan kondisi kesetimbangan antara permukaaan dan larutan yang dapat bersifat bolak-balik (reversible). Tetapi setelah dilakukan olah data dengan pengecekan melalui dua persamaan tersebut, maka persamaan Chapman yang lebih pas dan cocok untuk menyelesaikan kasus penelitian ini.

Dalam kasus penelitian ini, adsorpsi ion logam chrom oleh zeolit alam, baik yang telah teraktivasi atau belum, lebih dapat didekati dengan persamaan Chapman. Persamaan ini menyatakan adsorpsi sangat kecil pada konsentrasi rendah namun adsorpsi akan meningkat dengan semakin meningkatnya konsentrasi larutan. Fenomena ini dapat dilihat pada Tabel 1 dan Tabel 2 bahwa jika konsentrasi chrom dalam larutan mulamula (Co) kecil, maka chrom yang terjerap dalam zeolit (qe) juga kecil, hal ini disebabkan adanya reaksi lain dalam larutan seperti reaksi kompleksasi dengan ligan, mengakibatkan penjerapan adsorbat menjadi terhambat. Sebaliknya jika konsentrasi chrom dalam larutan mulamula (Co) besar, maka chrom yang terjerap dalam zeolit (qe) juga besar, hal ini disebabkan adanya gaya tarik menarik antar adsorbat yang mengakibatkan terjadi adsorpsi gabungan (cooperative adsorption) sehingga proses adsorpsi lebih optimal (Hinz, 2001). 
Tabel 3. Nilai Parameter Kesetimbangan Adsorpsi

\begin{tabular}{ccc|ccc}
\hline \multicolumn{2}{c|}{$\begin{array}{c}\text { Isoterm Adsorpsi Logam Chrom } \\
\text { oleh Zeolit Alam }\end{array}$} & \multicolumn{2}{c}{$\begin{array}{c}\text { Isoterm Adsorpsi Logam Chrom } \\
\text { oleh Zeolit Alam Teraktivasi Asam Sulfat }\end{array}$} \\
\hline Persamaan & \multicolumn{2}{c|}{ Konstanta } & Persamaan & \multicolumn{2}{c}{ Konstanta } \\
\hline \multirow{2}{*}{ Langmuir } & $\mathrm{a} \mathrm{(mg/g)}$ & 1,3116 & Langmuir & $\mathrm{a}(\mathrm{mg} / \mathrm{g})$ & 0,1064 \\
& $\mathrm{~b}(\mathrm{l} / \mathrm{mg})$ & 1,0791 & & $\mathrm{~b}(\mathrm{l} / \mathrm{mg})$ & 0,1438 \\
& $\mathrm{R}^{2}$ & 0,5179 & & $\mathrm{R}^{2}$ & 0,6223 \\
\hline \multirow{2}{*}{ Chapman } & $\alpha(\mathrm{mg} / \mathrm{g})$ & 0,2332 & Chapman & $\alpha(\mathrm{mg} / \mathrm{g})$ & 418,3117 \\
& $-\gamma \log e^{-\beta}$ & 0,3722 & & $-\gamma \log e^{-\beta}$ & 0,8752 \\
& $\mathrm{R}^{2}$ & 0,8964 & & $\mathrm{R}^{2}$ & 0,7516 \\
\hline
\end{tabular}

\section{Kesimpulan}

Dilihat dari $R$-squared value $\left(\mathrm{R}^{2}\right)$, persamaan Chapman lebih mendekati $R^{2}=$ 1 , itu artinya persamaan Chapman lebih cocok digunakan untuk menyelesaikan kasus adsorpsi logam chrom oleh zeolit, baik zeolit alam maupun zeolit alam teraktivasi asam sulfat.

Untuk menentukan daya serap zeolit maksimal, diambil dari persamaan Chapman yaitu nilai a nya. Dari kedua proses adsorpsi, nilai $\alpha$ yang terbesar yaitu isoterm adsorpsi logam chrom oleh zeolit teraktivasi asam sulfat, sebesar 418,3117 $\mathrm{mg} / \mathrm{g}$.

Zeolit alam yang sudah teraktivasi oleh asam sulfat lebih reaktif dibandingkan yang belum teraktivasi asam sulfat, karena dengan aktivasi akan memperbesar internal surface area, yang menyebabkan adsorben tersebut sangat porous sehingga kapasitas penjerapannya lebih besar.

\section{Ucapan Terima kasih}

Terima kasih penulis sampaikan kepada Universitas Widya Dharma Klaten, sebagai tempat kami melakukan penelitian ini, sekaligus sebagai penyandang dana dalam penelitian ini, dan juga semua pihak yang telah banyak membantu dalam penyelesaian penelitian ini.

\section{Daftar Pustaka}

Chatterjee, S., Dae, S., Lee, Min, W., Seung, H., dan Woo. (2010). Enhanced Molar Sorption Ratio for Naphthalene through the Impregnation of Surfactant into Chitosan Hydrogel Beads.
Bioresour. Technol. 101, 43154325.

Do, D.D. (1998). Adsorption Analysis: Equilibria and Kinetics. London: Imperial College Press.

Foo, K.Y., dan Hameed, B.H. (2010). Review Insights Into the Modeling of Adsorption Isotherm Systems. Chem. Eng. J. 156, 2-10.

Hinz, C. (2001). Description of Sorption Data with Isotherm Equations. Geoderma 99, 225-243.

Laksito, D.(2008). Kesetimbangan Fasa Amonia pada Air dan Sedimen di Sungai (Tesis). Tersedia dari Digital Library UGM Yogyakarta.

Lestari, D.Y. (2010). Kajian Modifikasi dan Karakteristik Zeolit Alam dari Berbagai Negara. Prosiding Seminar Nasional Kimia dan Pendidikan Kimia 2010 Yogyakarta. 30 Oktober 2010.

Metcalf dan Eddy. (2003). Wastewater Engineering Treatment and Reuse. (Fourth edition). New York: Mc. Graw hill.

Noll, K.E., Gounaris, V., dan Wang, S.H. (1992). Adsorption Technology for Air and Water Pollution Control, USA: Lewis Publisher, Inc.

Wahidatun, K.W., 2004, Adsorpsi Logam $\mathrm{Cr}$ dengan Zeolit Alam Teraktovasi Asam Sulfat, Skripsi diajukan kepada Jurusan Kimia Fakultas Sains dan Teknologi UIN Sunan Kalijaga, Yogyakarta. 